\title{
En Bloc Cervical Laminoplasty While Preserving the Posterior Structure with Arcocristectomy in Cervical Spondylotic Myelopathy
}

\author{
Abdulfettah TUMTURK, Ahmet KUCUK, Ahmet MENKU, Rahmi Kemal KOC \\ Erciyes University, Faculty of Medicine, Department of Neurosurgery, Kayseri, Turkey
}

\section{ABSTRACT}

AIM: To evaluate the clinical success of the en bloc laminoplasty and impact of the arcocristectomy on postoperative axial pain of the patients with cervical spondylotic myelopathy (CSM).

MATERIAL and METHODS: A retrospective review of 81 patients with CSM who underwent en bloc cervical laminoplasty while preserving posterior structure of the cervical spine during the period from 2007 to 2014 was performed. Arcocristectomy was performed if the 66-7 level was included in the surgery. The posterior spinal elements and muscles attached to the spinous process of $\mathrm{C} 2$ and $\mathrm{C} 7$ were preserved. Thus, postoperative deformity of the cervical spine could be avoided. The neurological status of the patients was assessed using the modified Japanese Orthopedic Association (JOA) scale. The neurological recovery rate was calculated according to the Hirabayashi method.

RESULTS: The mean modified JOA scale score was $11.4 \pm 2.4$ preoperatively and $15.0 \pm 3.9$ postoperatively. The neurological recovery rate was $68.6 \%$. C7 arcocristectomy was performed in 19 patients. No axial pain was noted in the first 2 postoperative months. Keyhole foraminotomies were performed in 11 patients and radicular pain completely resolved after surgery. Temporary C5 nerve root palsy was observed in 3 patients. Mean cervical spine lordosis was $10.6^{\circ} \pm 10.5^{\circ}$ preoperatively and $8.6^{\circ} \pm 9.5^{\circ}$ postoperatively. No postoperative spinal instability or kyphotic deformity was noted.

CONCLUSION: En bloc cervical laminoplasty while preserving posterior structure is useful in preventing postoperative spinal malalignment and axial pain. Arcocristectomy is an effective technique for the prevention of postoperative axial pain in patients with C6-7 spinal stenosis.

KEYWORDS: Cervical spondylotic myelopathy, En bloc laminoplasty, Axial pain, Kyphosis, Arcocristectomy

\section{INTRODUCTION}

$\mathrm{C}$ ervical spondylosis is a general term that describes commonly age-related chronic degenerative changes such as disc degeneration, osteophyte formation, thickness and/or ossification of the posterior longitudinal ligament (OPLL), degeneration of the facet joint and hypertrophy of the ligamentum flavum (17). Cervical spondylotic myelopathy (CSM) is the most common cause of myelopathy in adults and commonly results from a narrow spinal canal due to cervical spondylosis (4).
A decrease in the diameters of the cervical vertebral canal and intervertebral foraminas due to progressive degenerative changes can cause direct damage or secondary ischemic changes of the spinal cord and roots, which are responsible for the symptoms of CSM $(4,17)$. The symptoms of CSM include motor and sensory disturbances of the upper and lower extremities such as gait disturbances, loss of balance and difficulty with fine motor tasks of upper extremities, acquired spasticity, and axial neck, scapular and radicular pain (17). 
Decompression surgery via the anterior or posterior approach is the accepted treatment for CSM. The principal goals of the surgical treatment of CSM are both providing decompression of neural structures by increasing the canal diameter and restoring the spinal stability $(17,18,28)$.

Various techniques are recommended for the surgical treatment of CSM, including anterior cervical discectomy or corpectomy with fusion, laminectomy with or without fusion, and laminoplasty $(22,23)$. The anterior approach is recommended in patients in whom the disease affects one to three levels with anterior compression of the spinal cord and a straight or kyphotic spine $(10,18,31)$. The disadvantages of anterior surgery are the bone graft fusion and immobilization requirement, and low fusion rate in the elderly, diabetics and smokers, and adjacent segment disease $(18,31)$. The reported incidence of non-union after subtotal corpectomy is $0 \%$ to $27 \%(6,7)$. Another significant complication of anterior surgery is late deterioration secondary to degenerative changes at the adjacent levels (6). The adjacent segment disease rate is $2.9 \%$ per year, $25.6 \%$ per 10 years (9). The intradiscal pressure increases in the upper and lower segments during flexion (upper $73 \%$, lower $45 \%$ ). Moreover, mobility of the upper adjacent segment increases and this can lead to kyphosis (5). Dysphagia related to anterior surgery has also been reported as a complication (17).

Cervical laminectomy has long been considered as the standard treatment of CSM. Although it permits adequate decompression of the cervical spinal cord, potential adverse outcomes such as kyphosis, instability and epidural scar formation exist and may be responsible for postoperative head and neck pain and even delayed neurological deterioration. Laminoplasty was developed to widen the spinal canal without permanently removing the dorsal structures of the cervical spine to avoid the problems associated with laminectomy $(21,27)$.

The advantages of laminoplasty procedures include being appropriate for multilevel compression, no need for fusion, low risk of adjacent segment disease, and no complications of anterior surgery. Moreover, foraminotomy may be added to laminoplasty procedures in patients with radiculopathy $(20,28)$.

Laminoplasty is contraindicated in patients with kyphotic deformity and instability. Laminoplasty may contribute to spinal instability and can worsen the kyphosis in these patients and it has also been associated with mechanical neck pain $(21,28)$.

Various laminoplasty techniques have been described to avoid the disadvantages and complications of the procedure. All of these variations are designed to reposition the laminae for the purpose of expanding the spinal canal while retaining the dorsal elements to protect the dura from scar formation and to preserve postoperative cervical stability $(12,16,21-23$, 28).

The purpose of this study was to evaluate the clinical success of en bloc laminoplasty and the impact of arcocristectomy on postoperative axial pain in patients with CSM.

\section{MATERIAL and METHODS}

The study population consisted of 81 consecutive patients with CSM who underwent en bloc cervical laminoplasty while preserving the posterior structure during the period from 2007 to 2014. Radiological and clinical data were collected retrospectively. Patients who presented with symptoms and magnetic resonance imaging (MRI) findings consistent with CSM and without kyphosis were included in the study. Patients who had a straight cervical spine were also included. Patients with cord compression caused by an isolated central disc herniation, those with moderate or severe cervical kyphosis, or a history of tumor or injury were not included. MRI findings were consistent with myelopathy secondary to multisegmental cervical spondylotic stenosis in all patients that presented with the symptoms of myelopathy. Neurological condition was assessed by using modified Japanese Orthopedic Association (JOA) scale score (3). The postoperative recovery rate was calculated according to the Hirabayashi method (10): Recovery rate $(\%)=($ postoperative JOA-preoperative $\mathrm{JOA}) /(18$-preoperative JOA $) \times 100$. Pain was assessed by the visual analog scale (VAS). A neutral lateral radiography of the cervical spine was taken preoperatively and at last follow-up. Cervical spine lordosis was measured by calculating the angle between the line passing parallel to the lower endplate of $\mathrm{C} 2$ and upper endplate of C7 (14).

This study was carried out following the ethics committee approval, decision number 2016-145 and date 19.02.2016, of the Erciyes University Medical Faculty and a signed informed consent was obtained from all participants who were included in this study for the posterior cervical surgical procedure.

\section{Surgical Technique}

Laminoplasty was included in upper and lower levels of compression. The head was positioned prone and then immobilized by a Mayfield three-point head holder (Mayfield head holder; OMI surgical products, Cincinnati, OH, USA). A standard midline incision was made to expose the spinous processes from $\mathrm{C} 2$ to $\mathrm{C} 7$ for a typical C3-C6 laminoplasty. The subperiosteal dissection of muscles from spinous processes to middle of lateral mass was performed. All ligaments such as supraspinous and interspinous ligaments, ligamentum flavum and facet joint capsules were preserved. Muscles attached to the spinous processes of C2 and $\mathrm{C} 7$ were preserved. The junction of facet and lamina was identified. Keyhole foraminotomies were also performed in patients with radicular pain. A drill was used to drill a gutter at the medial margin of the facet through the cancellous portion, but not through the inner cortex on the side of the open-door "hinge". A gutter on the contralateral side was similarly made, except that it penetrated the inner cortex and the canal (as in complete laminectomy). Using angled curettes, the open side was slowly lifted. The "door" is generally opened on the more symptomatic side. Any sublaminar adhesions were dissected free. The elevated lamina was fixed to lateral mass by placing titanium mini-plates and screws.

If there was compression on C6-7 level, $\mathrm{C} 7$ arcocristectomy was performed. In the arcocristectomy technique, the upper 
half of the laminae and ligamentum flavum were removed bilaterally. The $\mathrm{C} 7$ spinous process and nuchal ligament were therefore preserved. The illustrative cases are presented in Figures $1 \mathrm{~A}-\mathrm{D}$ and $2 \mathrm{~A}-\mathrm{C}$.

All patients were mobilized on the postoperative $6^{\text {th }}$ to $8^{\text {th }}$ hours and wore a Nelson type collar for the first 2 weeks after surgery. Patients were discharged 24 to 48 hours after surgery.

\section{Statistical Analysis}

Descriptive statistical analysis was performed using R 3.1.1 (www.r-project.org, R Foundation for Statistical Computing, Vienna, Austria).

\section{- RESULTS}

The mean age of the enrolled patients was $59.9 \pm 11.8$ years. Most of the enrolled patients were male $(64 ; 79 \%)$ versus female $(17 ; 21 \%)$. The male/female ratio was $3.7 / 1$. The follow-up period ranged from 12 to 24 months (average 15 months). Mean JOA scale score was $11.4 \pm 2.4$ preoperatively and $15.0 \pm 3.9$ postoperatively. The JOA scale score did not worsen in any patient after surgery. The neurological recovery rate was $68.6 \%$. VAS was $2.1 \pm 1.1$ preoperatively and $1.3 \pm 0.6$ at 2 months of postoperative follow-up. Early postoperative axial neck pain was identified in most of patients but axial pain was decreased within 2 months. C7 arcocristectomy was performed in 19 patients. Keyhole foraminotomies were performed in 11 (bilateral in 2 and two levels in 5) patients. In all patients, preoperative radicular pain completely resolved after surgery. Temporary C5 nerve root palsy was observed in 3 patients. Mean cervical spine lordosis was $10.6^{\circ} \pm 10.5^{\circ}$ preoperatively and $8.6^{\circ} \pm 9.5^{\circ}$ postoperatively. Radiographically, a kyphotic deformity was not observed in any patient. No postoperative spinal instability was noted.

\section{DISCUSSION}

Although decompressive cervical laminectomy can effectively enlarge the narrow spinal canal, it has severe complications such as segmental instability, kyphotic deformity, perineural adhesions, and late neurological deterioration. The laminoplasty techniques, a surgical alternative to laminectomy, are developed with the aim of preserving posterior structure to avoid kyphotic deformity and preservation of the range of motion of the cervical spine $(10,19)$.

Indications for laminoplasty include multilevel cervical stenosis and compression to the spinal cord and OPLL (27). Cervical laminoplasty in patients with multisegmental spinal cord compression provides good neurological results and has a lower incidence of complications such as axial neck pain, loss of lordosis or kyphosis, instability and post-laminectomy membrane compared to laminectomy $(12,18,24,27,28)$.

Matsunaga et al.(20) reported a higher postoperative kyphosis rate in the patients who underwent laminectomy (11 of 37; $34 \%)$ compared to the patients who underwent laminoplasty (4 of $64 ; 7 \%$ ). Heller et al. (8) reported that laminoplasty has some advantages in preserving the postoperative range of motion over laminectomy. Although kyphotic deformity is less seen after laminoplasty procedures compared to laminectomy, it is one of the major shortcomings of laminoplasty. Kimura et al. (16) stated that one of the plausible reasons for late deterioration was kyphotic deformity or instability after surgery. Postoperative kyphosis and segmental instability can cause neurological problems and are believed mainly to result from neck muscle and ligamentous disruption $(12,18,27)$.

Disruption of posterior tension band and resection of $50 \%$ of the facet joint and capsule (32), and incorrect patient selection (patients with a lordotic angle of $<10^{\circ}$ and with kyphotic deformity) play an important role in postoperative kyphosis and resultant axial pain (28).

Adverse radiologic changes and axial neck pain after cervical laminoplasty have been reported as mostly resulting from neck muscle disruption, particularly detachment of muscle insertions to the $C 2$ and $C 7$ spinous processes $(14,25,27,29)$. The possible causes of axial pain after laminoplasty were diffuse atrophy of the muscles attached to the nuchal ligament, ischemia of the shoulder muscles, and delayed union in the facet joints (13).

There are five muscles that attach to the $\mathrm{C} 2$ spinous process: the rectus capitis posterior major, the obliquus capitis inferior, the semispinalis cervicis, the multifidus and the interspinalis muscles. These are the extensor muscles attached to the C2 spinous process, which have a role in extending and stabilizing the head and neck. Disruption of the extensor musculature of $\mathrm{C} 2$ during posterior surgery plays an important role in postoperative malalignment of the cervical spine $(14,15,26)$.

The ligamentum nuchae constitutes a body of dense connective tissue from the bilaminar aponeuroses of the trapezius, rhomboideus minor, serratus posterior superior, and splenius capitis (15). The transverse portion of the trapezius muscle attaches from $\mathrm{C} 7$ to $\mathrm{T} 5$ spinous process and the rhomboid minor muscle attaches to $\mathrm{C} 7$ and $\mathrm{T} 1$ spinous processes. Because the $\mathrm{C} 7$ spinous process has a critical role as a fulcrum for shoulder suspensory muscles, postoperative axial neck pain may be caused by injury to shoulder suspensory muscles after laminoplasty procedures including $\mathrm{C} 7$ spinous processes (25).

In this study, the posterior spinal elements such as spinous process, supraspinous and interspinous ligaments, ligamentum flavum and muscles attached to spinous process of $\mathrm{C} 2$ and $\mathrm{C} 7$ were preserved. Thus, postoperative deformity of the cervical spine could be avoided by means of posterior tension band preservation. The cervical spine was kept more stable compared with the results obtained after other expansive laminoplasty procedures (14).

The cervical lordosis decreases by age, particularly between 50-60 years of age. The disc physiologically loses its elasticity and resiliency because of the dehydration during the normal life cycle. This alters the height and shape of the discs, which play a role in the loss of lordosis. The ligament contraction occurs by aging and this can also contribute to the changes in posture (2). In this study, $2^{\circ}$ loss of lordosis angle was noted (from $10.6^{\circ} \pm 10.5^{\circ}$ to $8.6^{\circ} \pm 9.5^{\circ}$ ). This decrease in lordosis may be attributable not only surgery but also to the changes related to aging. 

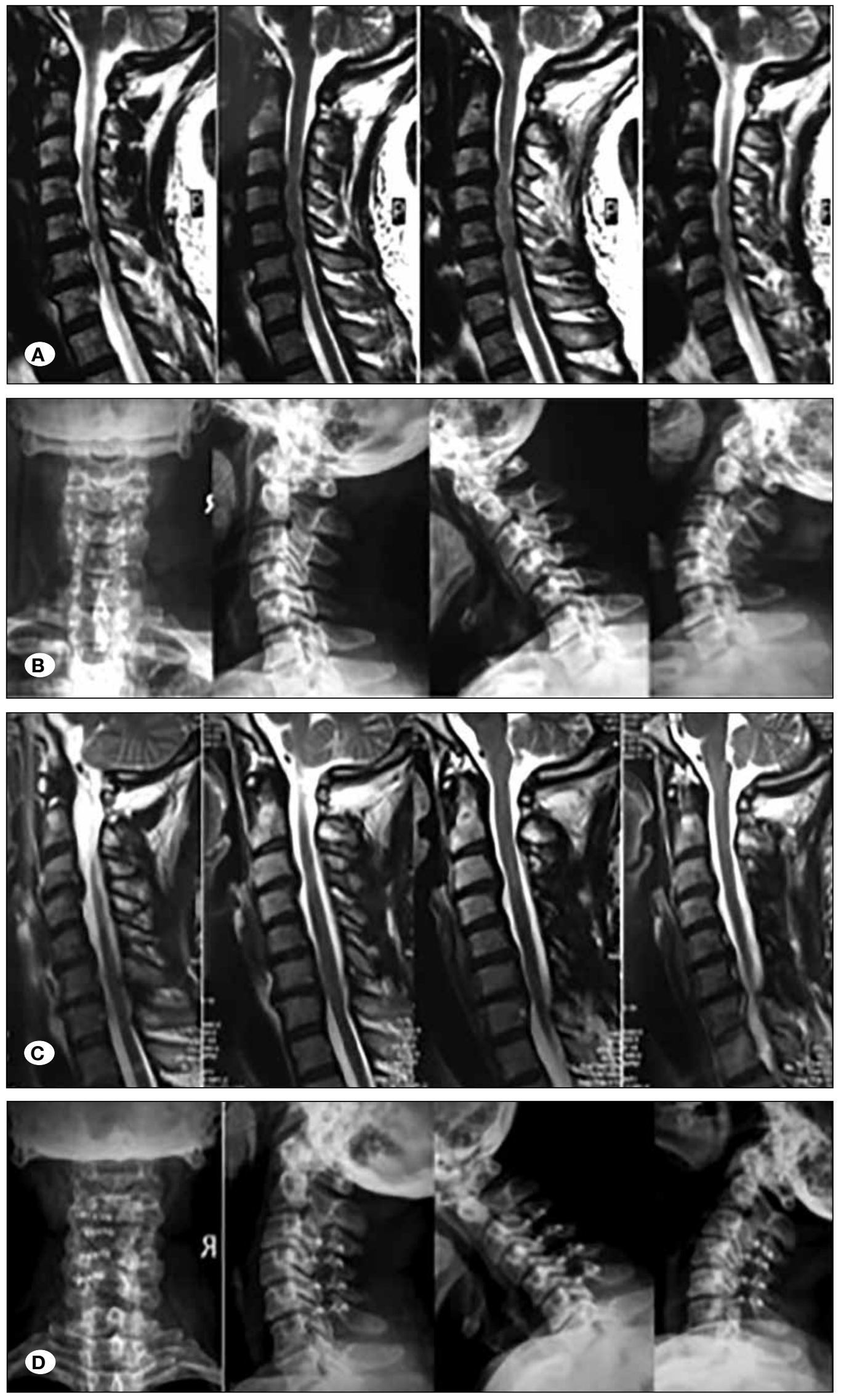

Figure 1: A) A 43-year-old female patient. Sagittal T2-weighted MR images show multilevel spinal cord compression at the C34, C4-5, C5-6 levels. The patient's modified JOA score was 13. B) Anteroposterior, lateral, hyperflexion and hyperextension lateral preoperative cervical films are shown. The patient's preoperative lordotic angle was $12^{\circ}$. C) A standard C3-6 en bloc laminoplasty was performed. Her postoperative modified JOA score was 18.

Sagittal T2-weighted MR images show adequate canal decompression after surgery. D) Anteroposterior, lateral, hyperflexion and hyperextension postoperative cervical films are shown. The patient's postoperative lordotic angle was $10^{\circ}$. 

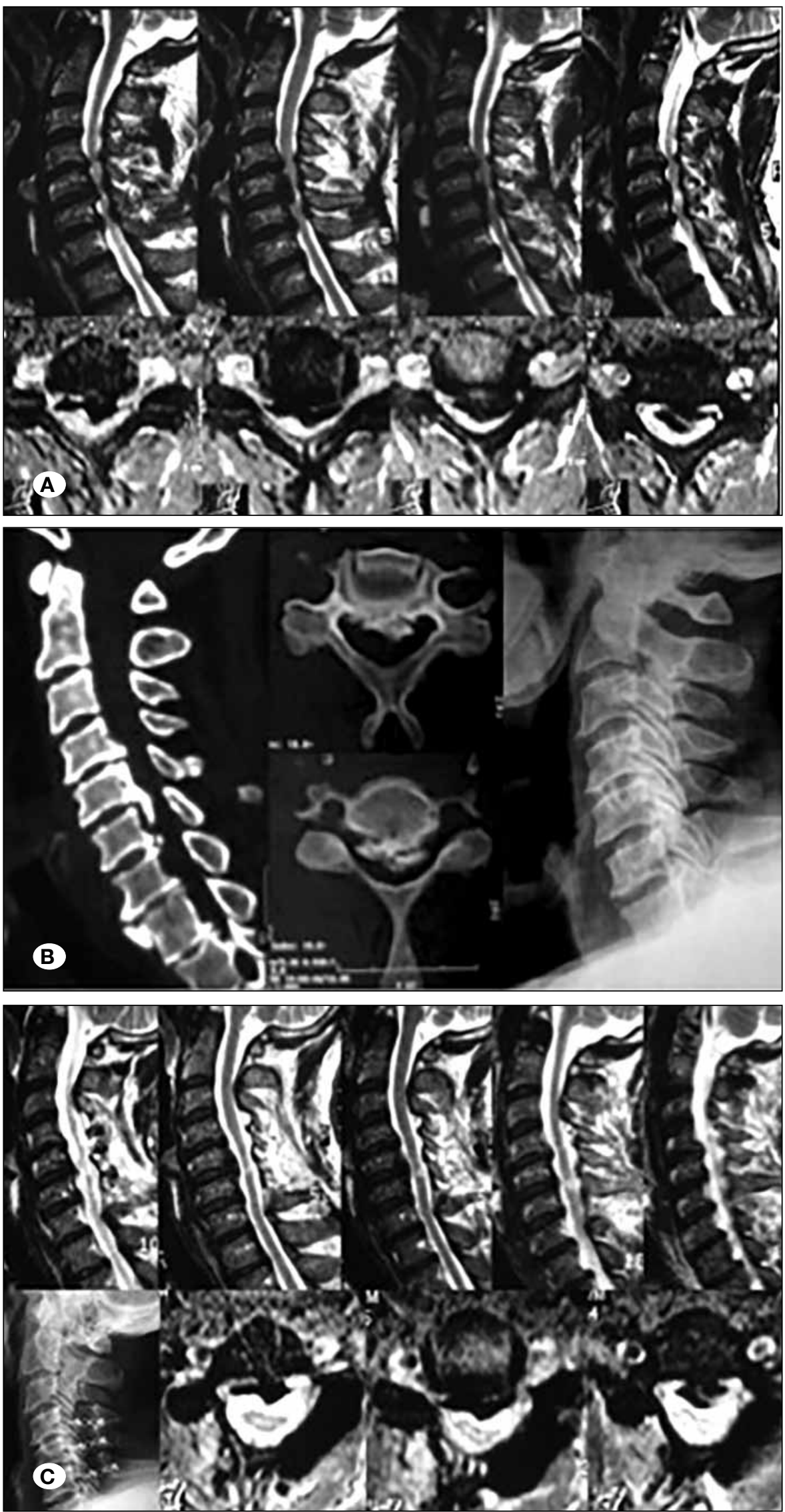

Figure 2: A) A 51 years-old male patient. Sagittal T2 weighted MR images show significant spinal cord compression at the C4-5, C5-6 and C6-7 levels by the ossified posterior longitudinal ligamentum (OPLL). The patients' modified JOA scale score was 10. B) Sagittal and axial CT scans show multiple OPLL, particularly at the C5-6 level, and resultant spinal canal stenosis. On lateral cervical plain film, his lordotic angle was $16^{\circ}$ preoperatively. C) A standard C4-6 laminoplasty and C7 arcocristectomy were performed. The postoperative sagittal and axial MR images confirm adequate canal decompression after surgery. On lateral cervical plain film, the patient's postoperative lordotic angle was $18^{\circ}$. His postoperative modified JOA scale score was 16 
Another complication associated with laminoplasty is C5 root palsy. Posterior migration of the spinal cord and resultant nerve root tethering has been suggested as the major cause of this complication (30). We observed with this complication in three patients. This is generally a transient complication and all of them recovered within 2 months. After initial observation of this complication, we have performed C4-5 foraminotomy immediately after en bloc laminoplasty to avoid this complication. We have not observed this complication after this process.

The technique of arcocristectomy was introduced as an alternative posterior surgical approach to laminoplasty and laminectomy in patients with multilevel CSM in order to prevent kyphotic deformity. In this technique, only the upper half of the cervical laminae and ligamentum flavum is removed to widen the spinal canal diameter (1). We have applied this technique to the patients whose $\mathrm{C} 7$ level must be included to surgical area. The supraspinous, the interspinous ligaments and muscle attachment to $\mathrm{C} 7$ spinous process were always preserved.

Hosono et al. (11) have reported that axial neck pain rate was 29\% in C3-7 laminoplasty and 5.4\% in C3-6 laminoplasty. The results of arcocristectomy while preserving the nuchal ligament provides clinical and radiological outcomes that clearly superior to those of conventional C7 laminoplasty.

The posterior approach is an appropriate surgical option if multilevel spinal cord compression and predominant posterior spinal cord compression exist and the patient has a good lordosis too (18). En bloc cervical laminoplasty while preserving posterior structures of the cervical spine has allowed us to obtain very successful results and applying the technique of arcocristectomy contributed to the good results as well.

\section{CONCLUSION}

En bloc cervical laminoplasty while preserving the posterior structure is useful to avoid postoperative spinal malalignment and axial pain. Arcocristectomy is an effective technique for the prevention of postoperative axial pain in patients with C6-7 spinal stenosis.

\section{REFERENCES}

1. Amaral SH, Silva MN, Giraldi M, Viterbo MBS, Pereira CAB: Multiple cervical arcocristectomies for the treatment of cervical spondylotic myelopathy: Surgical technique and results. J Neurosurg Spine 7:503-508, 2007

2. Ball JM, Cagle P, Johnson BE, Lucasey C, Lukert BP: Spinal extension exercises prevent natural progression of kyphosis. Osteoporos Int 20:481-489, 2009

3. Benzel EC, Lancon J, Kesterson L, Haden T: Cervical laminectomy and dentate ligament section for cervical spondylotic myelopathy. J Spinal Disord 4:286-295, 1991

4. Bohlman HH, Emery SE: The pathophysiology of cervical spondylosis and myelopathy. Spine 13:843- 846, 2001
5. Eck JC, Humphreys SC, Lim TH, Jeong ST, Kim JG, Hodges $\mathrm{SD}$, An HS: Biomechanical study on the effect of cervical spine fusion on adjacent-level intradiscal pressure and segmental motion. Spine 27:2431-2434, 2002

6. Emery SE, Bohlman HH, Bolesta MJ, Jones SK: Anterior cervical decompression and arthrodesis for the treatment of cervical spondylotic myelopathy. J Bone Joint Surg (Am) 80:941-951, 1998

7. Fernyhough JC, White $\mathrm{JI}$, LaRocca H: Fusion rate in multilevel cervical spondylosis comparing allograft fibula with autograft fibula in 126 patients. Spine 16:S561-564, 1991

8. Heller JG, Edwards CC II, Murakami H, Rodts GE: Laminoplasty versus laminectomy and fusion for multilevel cervical myelopathy: An independent matched cohort analysis. Spine 26:1330-1336, 2001

9. Hilibrand AS, Carlson GD, Palumbo MA, Jones PK, Bohlman $\mathrm{HH}$ : Radiculopathy and myelopathy at segments adjacent to the site of a previous anterior cervical arthrodesis. J Bone Joint Surg Am 81: 519 -528, 1999

10. Hirabayashi K, Miyagawa J, Satomi K, Maruyama T, Wakano $\mathrm{K}$ : Operative results and postoperative progression of ossification among patients with ossification of cervical posterior longitudinal ligament. Spine 6:354-364, 1981

11. Hosono N, Sakaura H, Mukai Y, Fujii R, Yoshikawa H: C3-6 laminoplasty takes over C3-7 laminoplasty with significantly lower incidence of axial neck pain. Eur Spine J 15: 13751379, 2006

12. Hosono N, Sakaura H, Mukai Y, Ishii T, Yoshikawa H: En bloc laminoplasty without dissection of paraspinal muscles. J Neurosurg Spine 3:29-33, 2005

13. Hosono N, Yonenobu K, Ono K: Neck and shoulder pain after laminoplasty: A noticeable complication. Spine 21:19691973, 1996

14. lizuka $H$, Nakajima T, lizuka $Y$, Sorimachi $Y$, Ara T, Nishinome M, Takagishi K: Cervical malalignment after laminoplasty: Relationship to deep extensor musculature of the cervical spine and neurological outcome. J Neurosurg Spine 15:610614, 2007

15. Johnson GM, Zhang M, Jones DG: The fine connective tissue architecture of the human ligamentum nuchae. Spine 25:5-9, 2000

16. Kimura I, Shingu H, Nasu Y: Long-term follow-up of cervical spondylotic myelopathy treated by canal-expansive laminoplasty. J Bone Joint Surg (Br) 77:956-961, 1995

17. Klineberg E: Cervical spondylotic myelopathy: A review of the evidence. Orthop Clin N Am 41:193-202, 2010

18. König SA, Spetzger U: Surgical management of cervical spondylotic myelopathy indications for anterior, posterior or combined procedures for decompression and stabilization. Acta Neurochir 156:253-258, 2014

19. Machino M, Yukawa Y, Hida T, Ito K, Nakashima H, Kanbara S, Morita D, Kato F: Cervical alignment and range of motion after laminoplasty. Spine 37:E1243-E1250, 2012

20. Matsunaga S, Sakou T, Nakanisi K: Analysis of the cervical spine alignment following laminoplasty and laminectomy. Spinal Cord 37:20-24, 1999 
Tumturk A. et al: En Bloc Cervical Laminoplasty

21. Mitsunaga LK, Klineberg EO, Gupta MC: Laminoplasty techniques for the treatment of multilevel cervical stenosis. Adv Orthop 30:791-796, 2012

22. Mummaneni PV, Kaiser MG, Matz PG, Anderson PA, Groff, MW, Heary RF, Holly LT, Ryken TC, Choudhri TF, Vresilovic EJ, Resnick DK: Cervical surgical techniques for the treatment of cervical spondylotic myelopathy. J Neurosurg Spine 11:130141, 2009

23. Ratliff JK, Cooper PR: Cervical laminoplasty: A critical review. J Neurosurg Spine 98:230-238, 2003

24. Ryken TC, Heary RF, Matz PG, Anderson PA, Groff MW, Holly LT, Kaiser MG, Mummaneni PV, Choudhri TF, Vresilovic EJ, Resnick DK: Cervical laminectomy for the treatment of cervical degenerative myelopathy. J Neurosurg Spine 11:142149, 2009

25. Sakaura H, Hosono N, Mukai Y, Fujimori T, Iwasaki M, Yoshikawa $\mathrm{H}$ : Preservation of muscles attached to the $\mathrm{C} 2$ and C7 spinous processes rather than subaxial deep extensors reduces adverse effects after cervical laminoplasty. Spine 35: E782-E786, 2010

26. Shiraishi T, Yato Y: New double-door laminoplasty procedure for the axis to preserve all muscular attachments to the spinous process. Neurosurg Focus 12:E9, 2002
27. Steinmetz MP, Resnick DK: Cervical laminoplasty. The Spine J 6:274S-281S, 2006

28. Suk KS, Kim KT, Lee JH, Lee SH, Lim YJ, Kim JS: Sagittal alignment of the cervical spine after the laminoplasty. Spine 32:E656-E660,2007

29. Takeuchi K, Yokoyama T, Aburakawa S, Saito A, Numasawa T, Iwasaki T, Itabashi T, Okada A, Ito J, Ueyama K, Toh S: Axial symptoms after cervical laminoplasty with C3 laminectomy compared with conventional C3-C7 laminoplasty: A modified laminoplasty preserving the semispinalis cervicis inserted into axis. Spine 30:2544-2549, 2005

30. Tsuzuki N, Saiki K, Okai K: Paralysis of the arm after posterior decompression of the cervical spinal cord. II. Analyses of clinical findings. Eur Spine J 2:197-202, 1993

31. Wada E, Suzuki S, Kanazawa A, Matsuoka T, Miyamoto S, Yonenobu K: Subtotal corpectomy versus laminoplasty for multilevel cervical spondylotic myelopathy: A long-term follow-up study over 10 years. Spine 26:1443-1447, 2001

32. Zdeblick TA, Zou D, Warden KE, McCabe R, Kunz D, Vanderby R: Cervical stability after foraminotomy. A biomechanical in vitro analysis. J Bone Joint Surg Am 74: 22 -27, 1992 